CrossMark

\&click for updates

Cite this: Catal. Sci. Technol., 2016, 6,4863

\section{Insights into the carbon catalyzed direct dehydrogenation of isobutane by employing modified OMCs ${ }^{\dagger}$}

\author{
Zhongshen Zhang, Yang Li, Junhui Wang, Hongling Yang, Na Li, Chunyan Ma and \\ Zhengping Hao*
}

Received 28th November 2015, Accepted 28th February 2016

DOI: $10.1039 /$ c5cy02058a

www.rsc.org/catalysis

\begin{abstract}
To identify the possible reaction mechanism of carbon-based catalysts for the isobutane direct dehydrogenation (DDH) reaction, a series of modified ordered mesoporous carbons (OMCs) with different surface oxygen contents were prepared and employed as representative catalysts. The OMCs were synthesized by employing SBA-15 as template, and the different oxygen contents were realized by the subsequent oxidation and reduction treatments. According to the characterization results, the treatments have significantly influenced the surface properties, while no obvious change was observed in their pore structure. The differences of surface properties due to the different treatments, and the changes in pore structure and oxygen contents after being used as catalysts, were employed to identify the possible active sites in the carbon catalyzed direct dehydrogenation (DDH) of isobutane. The carbon-based catalysts kept a good stability over a long period of time. The activity was mainly provided by the defects/vacancies on the surface of the carbon materials, and generated coke was also found to be active at a relatively lower level.
\end{abstract}

\section{Introduction}

Owing to their versatile and extensive use as chemical building blocks, light olefins $\left(\mathrm{C}_{2}-\mathrm{C}_{4}\right)$ occupy an important place in the chemical industry. ${ }^{1,2}$ Originally, the light olefins were commonly provided as byproducts through the steam cracking and fluid catalytic cracking (FCC) of naphtha and other oil. ${ }^{3}$ However, the output of these processes as byproducts cannot meet the increasing demand of the market. So in recent decades great efforts have been contributed to the research of catalytic dehydrogenation of light alkane to olefins., ${ }^{4,5}$

Isobutene is regarded as one of the most useful intermediates among the $\mathrm{C}_{4}$ hydrocarbons. Catalytic dehydrogenation of isobutane is a promising way to produce large amounts of isobutene. There are mainly three categories of dehydrogenation, ${ }^{6}$ namely, direct dehydrogenation, ${ }^{7,8}$ oxidative dehydrogenation $^{9,10}$ and membrane catalytic reaction. ${ }^{11}$ The main factor that limits the development of the isobutane dehydrogenation process might be the lack of appropriate catalysts. In recent years, many materials have been investigated as cat-

Department of Environmental Nano-Materials, Research Center for EcoEnvironmental Sciences, Chinese Academy of Sciences, Beijing 100085, China. E-mail: zpinghao@rcees.ac.cn; Fax: +86 10 62923564; Tel: +86 1062923564 $\dagger$ Electronic supplementary information (ESI) available. See DOI: 10.1039/ c5cy02058a alysts for the dehydrogenation of light alkanes. ${ }^{12,13}$ For the patented industrial processes, alumina supported noble metal catalyst ${ }^{14}$ and chromic oxides ${ }^{15}$ are currently being industrialized to produce light olefins. However, they also have their own shortcomings, despite their good dehydrogenation performance; noble metal is very expensive and chromium oxide is toxic. What's more, the frequent (15-30 minutes) regeneration $^{12}$ of catalyst might be an energy consumptive process. Other substitute catalysts currently explored, such as vanadium oxide, ${ }^{16,17}$ pyrophosphate ${ }^{18,19}$ and molybdate ${ }^{20,21}$ suffer from poor conversion, low selectivity or quick deactivation.

A proper catalytic material that could maintain a good conversion as well as high selectivity for a long period of time is needed. Among various possible materials, porous carbons are widely used not only in the section of electrochemistry ${ }^{22}$ and adsorption, ${ }^{23}$ but also in the field of catalysis, ${ }^{24,25}$ due to their distinct advantages, such as low price and reproducibility, environmental friendliness, high specific surface area, excellent thermal and chemical stability, adjustable pore structure and surface properties. Of the numerous carbon materials, SBA-15 templated ordered mesoporous carbon (OMC) is a well-studied carbon material. ${ }^{26}$ The structures have a specific and regular form, and a slight change of pore structure could be clearly reflected in the characterization such as SEM and PSD. Though other carbon materials might have a higher surface area or better activity, due to their cluttered structure it is hard to identify the ascription of 
changes. So OMC is a promising model material to study the catalytic reaction of carbon-based catalysts.

Researches about carbon catalyzed butane dehydrogenation are getting more and more comprehensive. ${ }^{27}$ Lots of studies about the carbon-based catalysts for oxidative isobutane dehydrogenation are reported, ${ }^{28,29}$ but to our knowledge research on carbon catalyzed direct isobutane dehydrogenation are insufficient. Velásquez ${ }^{30}$ used activated carbon in the direct isobutane dehydrogenation as a controlled trial, but the reaction temperature was not at a proper value, or they would testify the good activity of porous carbons. Researches about carbon-based catalysts for $n$-butane dehydrogenation might also give some significant guidance to the isobutane dehydrogenation. $\mathrm{Su}^{31}$ etc. have reported that the surface oxygenic functional groups have reaction activity on the reaction of oxidative dehydrogenation of $n$-butane by employing surface modified carbon nanotubes. McGregor ${ }^{32}$ etc. found that the deposited coke was active in the dehydrogenation of $n$-butane on $\mathrm{VO}_{x} / \mathrm{Al}_{2} \mathrm{O}_{3}$ catalyst. $\mathrm{Su}^{33}$ etc. reported that the selective site for carbon-catalyzed oxidative dehydrogenation of $n$-butane was formed during $\mathrm{sp}^{3}$-to- $\mathrm{sp}^{2}$ lattice rearrangement. However, for these oxidative dehydrogenations of butane, the reaction temperatures needed to be kept below $400{ }^{\circ} \mathrm{C}$ to avoid the combustion of the carbon-based catalyst. The conversion and selectivity were around $13 \%$ and $50 \%$, respectively, which cannot meet the requirements of the application. So carbon catalyzed direct isobutane dehydrogenation without the use of oxygen might be a promising solution.
This study is a continuation of our last work. In our recently published paper, ${ }^{34}$ the good reaction activity and retention rate of carbon-based catalysts in the direct isobutane dehydrogenation were reported. In this study, to further study the possible mechanism of carbon catalyzed DDH, a series of modified OMCs with a specific regular structure and different oxygen contents were prepared. By employing OMCs with and without surface oxygen-containing functional groups, this study attempts to rank the contributions of the possible influencing factors, namely, the carbon itself, the generated coke and the oxygen containing groups.

\section{Experimental details}

\subsection{Material preparation}

The synthesis process was performed using 2-D hexagonal $(P 6 \mathrm{~mm})$ mesoporous silica SBA-15 as a hard template and sucrose as a carbon source. The synthesis of SBA-15 and OMC8 were based on the literature of Zhao et al. ${ }^{35}$ and Xing et al., ${ }^{36}$ respectively. The schematic diagram of synthesis route for modified OMCs is shown in Fig. 1.

In a typical synthesis procedure, $1.25 \mathrm{~g}$ sucrose and $0.14 \mathrm{~g}$ $\mathrm{H}_{2} \mathrm{SO}_{4}(98 \%)$ was dissolved in $5.0 \mathrm{~mL} \mathrm{H}_{2} \mathrm{O}$ under stirring, and then mixed homogeneously with $1 \mathrm{~g}$ SBA-15, assisted by ultrasonic treatment for 30 minutes. The mixture was dried and pre-carbonized in an oven for $6 \mathrm{~h}$ at $100{ }^{\circ} \mathrm{C}$ and $160{ }^{\circ} \mathrm{C}$, respectively. The impregnation and drying process was implemented again using 0.66 times the dosage with the
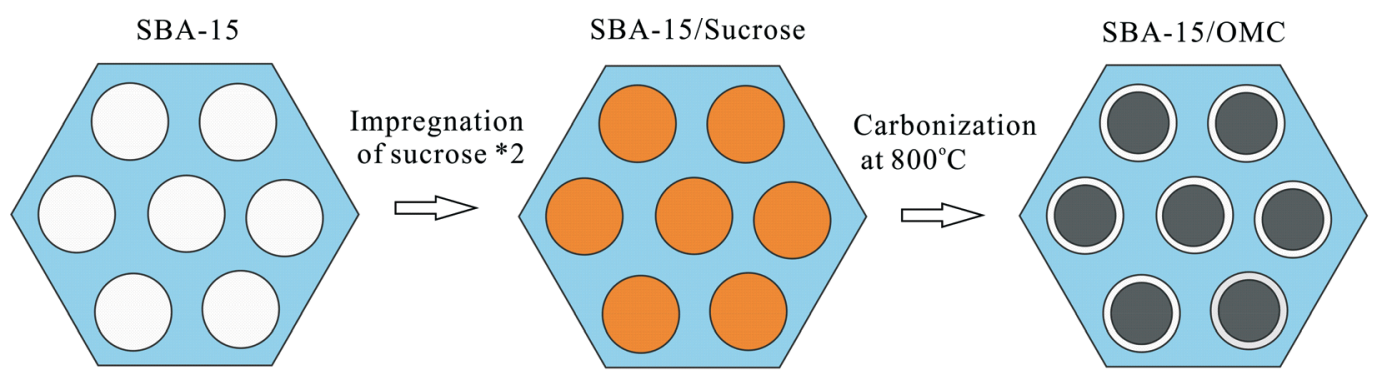

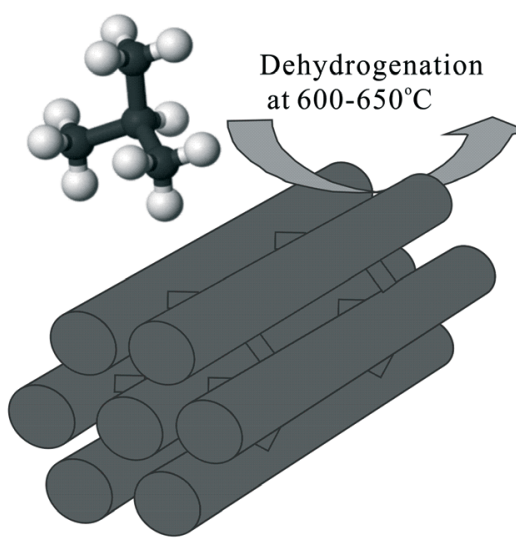

$\mathrm{OMC} 8$ / OMC- $\mathrm{H}_{2} / \mathrm{OMC}-\mathrm{H}_{2} \mathrm{O}_{2}$

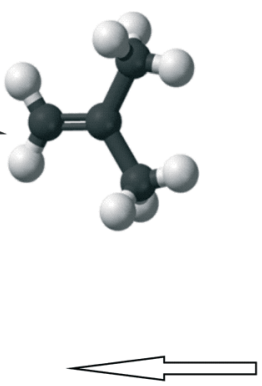

1. Not treated

2. Treated by $\mathrm{H}_{2}$

3. Treated by $\mathrm{H}_{2} \mathrm{O}_{2}$

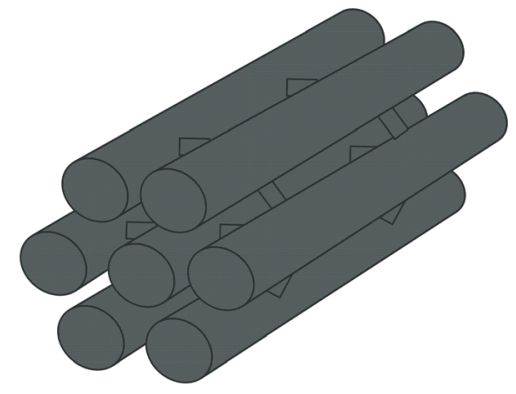

OMC8

Fig. 1 Illustration of the preparation method of OMCs for isobutane DDH application. 
same ratio. The mixture was carbonized at $800{ }^{\circ} \mathrm{C}$ for 2 hours $\left(3{ }^{\circ} \mathrm{C} \min ^{-1}\right.$ ), under an $\mathrm{N}_{2}$ atmosphere. The silica templates were removed by $20 \% \mathrm{HF}$ aqueous solution. Then the composites were washed with deionized water until neutral $\mathrm{pH}$, before drying at $80{ }^{\circ} \mathrm{C}$ for 10 hours. The obtained ordered mesoporous carbon material was named as OMC8.

To obtain different surface properties, the synthesized OMC8 was reduced by $\mathrm{H}_{2}$ at $800{ }^{\circ} \mathrm{C}$ for 2 hours and oxidized by $\mathrm{H}_{2} \mathrm{O}_{2}$ at room temperature for 5 hours, respectively. The thus-prepared materials were referred to as $\mathrm{OMC}-\mathrm{H}_{2}$ and OMC- $\mathrm{H}_{2} \mathrm{O}_{2}$, which referred to their corresponding treatment conditions. To study the possible reaction mechanism of dehydrogenation, OMC8 was collected after being used as catalyst at $620{ }^{\circ} \mathrm{C}$ for a long period of time (4000 minutes), and was named as OMC-Used. The name OMCs was used as the general term for OMC8, OMC- $\mathrm{H}_{2}$, and $\mathrm{OMC}-\mathrm{H}_{2} \mathrm{O}_{2}$.

\subsection{Material characterizations}

In this work, high resolution field emission scanning electron microscope (FESEM) and scanning electron microscope energy dispersive X-ray spectra (SEM-EDS) analysis were carried out on a Hitachi SU 8020 UHR to visualize the morphology and analyze the elemental content of the samples. The pore structure properties were characterized by a Micromeritics ASAP 2020HD static volumetric analyzer at $-196{ }^{\circ} \mathrm{C}$. Before measurements, the samples were degassed at $300{ }^{\circ} \mathrm{C}$ for $5 \mathrm{~h}$ under vacuum. The surface area and the pore size distributions (PSDs) of samples were calculated using BET and BJH methods, respectively. The regularity of samples' mesopores were characterized by X-ray diffraction (X'Pert PRO MPD, Panalytical, Netherlands) using $\mathrm{Cu} \mathrm{K} \alpha$ radiation $(\lambda=1.5408)$. X-ray photoelectron spectroscopy (XPS) was collected on an Axis Ultra instrument (Kratos Analytical) with a resolution ratio of $0.48 \mathrm{eV}$. Raman measurements were conducted with a Renishaw InVia Raman microscope equipped with $532 \mathrm{~nm}$ laser lines as the excitation source. Fourier transform infrared (FTIR) spectra were recorded in a transmission mode using a Nicolet 8700 FTIR spectrometer with $\mathrm{KBr}$ pellets.

\subsection{Reaction procedure}

The catalytic experiments were performed in a quartz tube fixed bed reactor (inner diameter $=6 \mathrm{~mm}$ ). For each measurement, $0.1 \mathrm{~g}$ of catalyst ( $c a .40 \mathrm{mesh}$ ) was loaded into the reactor. The reaction gas was composed of standard gases in the molar ratio of $\mathrm{N}_{2} / \mathrm{C}_{4} \mathrm{H}_{10}=95 / 5$ in a cylinder, and the flow rate was calibrated by a mass flow controller at $20 \mathrm{~mL} \mathrm{~min} \mathrm{~m}^{-1}$ (weight hourly space velocity of $6000 \mathrm{~mL} \mathrm{~g}^{-1} \mathrm{~h}^{-1}$ ). The reaction was performed at $P=0.4 \mathrm{MPa}$. The products were analyzed by on-line gas chromatography (Agilent 7890A) equipped with a Poropak $\mathrm{N}$ column (Agilent, HP-PLOT $\mathrm{Al}_{2} \mathrm{O}_{3}$ S) and a flame ionization detector, and high purity $\mathrm{N}_{2}$ was used as the carrier gas. To find the suitable reaction temperature, the activities of catalysts were tested in the range of 600-700 ${ }^{\circ} \mathrm{C}$, and at each ten degrees centigrade the tempera- ture was held for 60 minutes. After that the reaction temperature was fixed at $620{ }^{\circ} \mathrm{C}$ as a representative temperature. Based on the chromatographic data, the total conversion, yield and selectivity of isobutene were calculated by mole ratio, using the literature formulae. ${ }^{34}$

\section{Results and discussion}

\subsection{Textural characterizations}

Field emission scanning electron microscopy (FESEM) was employed to intuitively study the microscopic morphology of SBA-15 and OMCs as shown in Fig. 2 and Fig. S1. $\dagger$ As reflected in Fig. 2(a), the mesopore channels of SBA-15 are of a uniform size, indicating the good synthesis of the template. The nanostructures of OMC8 (Fig. 2b), OMC-H $\mathrm{O}_{2}$ (Fig. S1c $\dagger$ ) and $\mathrm{OMC}-\mathrm{H}_{2} \mathrm{O}_{2}$ (Fig. S1d $\dagger$ ) are the same; they are all constituted of the orderly arranged uniform nanorods, indicating that the modification of OMC8 by using $\mathrm{H}_{2}$ at $800{ }^{\circ} \mathrm{C}$ or $\mathrm{H}_{2} \mathrm{O}_{2}$ did not obviously change its pore structure. It is notable that the slits formed between the carbon nanorods give the OMCs a kind of open type pore structure, which was the inverted architecture of their template SBA-15. Fig. 2(c) and (d) are the images of OMC-Used; obvious changes were observed after being used as a catalyst for a long period of time. Compared with OMC8 (Fig. 2b), many convex protrusions were observed on the surface of the nanorods of OMC-Used. These convex protrusions might be the generated coke during catalytic reaction.

The $\mathrm{N}_{2}$ adsorption-desorption isotherms and pore size distribution of synthesized materials are shown in Fig. 3(a). All of the samples have characteristics of a type IV isotherm, showing a quick rise at intermediate pressure, indicating the mesoporous nature of these materials. As shown in Fig. 3(b), the pore size distribution of the OMCs are concentrated at ca. $3.5 \mathrm{~nm}$, indicating the hard template synthesis method had effectively provided the OMCs with a well arranged mesopore structure. The pore size distribution of $\mathrm{OMC} 8, \mathrm{OMC}^{-} \mathrm{H}_{2}$ and $\mathrm{OMC}-\mathrm{H}_{2} \mathrm{O}_{2}$ are almost overlapping, indicating the same pore structure of OMCs. For OMC-Used, an obvious shift of the concentrated pores to lower size were observed. This shift might be caused by the generation of coke, which had been visually observed by FESEM in Fig. 2(d).

Small angle XRD diagrams of synthesized SBA-15 and OMCs are shown in Fig. 3(c). For all the samples three obvious diffraction peaks in the range of $0.8-2^{\circ}$ were observed, which could be assigned to (100), (110), and (200) diffractions of their 2-D hexagonal space group $(p 6 \mathrm{~mm})$. The small angle X-ray diffraction patterns proved that the OMCs have successfully replicated the pore structure of SBA-15, and after modification the long-range order of the OMCs was well preserved. As shown in Fig. 3(d), the wide angle XRD pattern of OMC8 showed a feature of general amorphous carbon. For the OMC-Used sample, the diffraction peaks at ca. 24-26 and $43^{\circ}$ degrees were enhanced, indicating the generation of a new kind of carbon phase which is more like graphite than OMC8. 


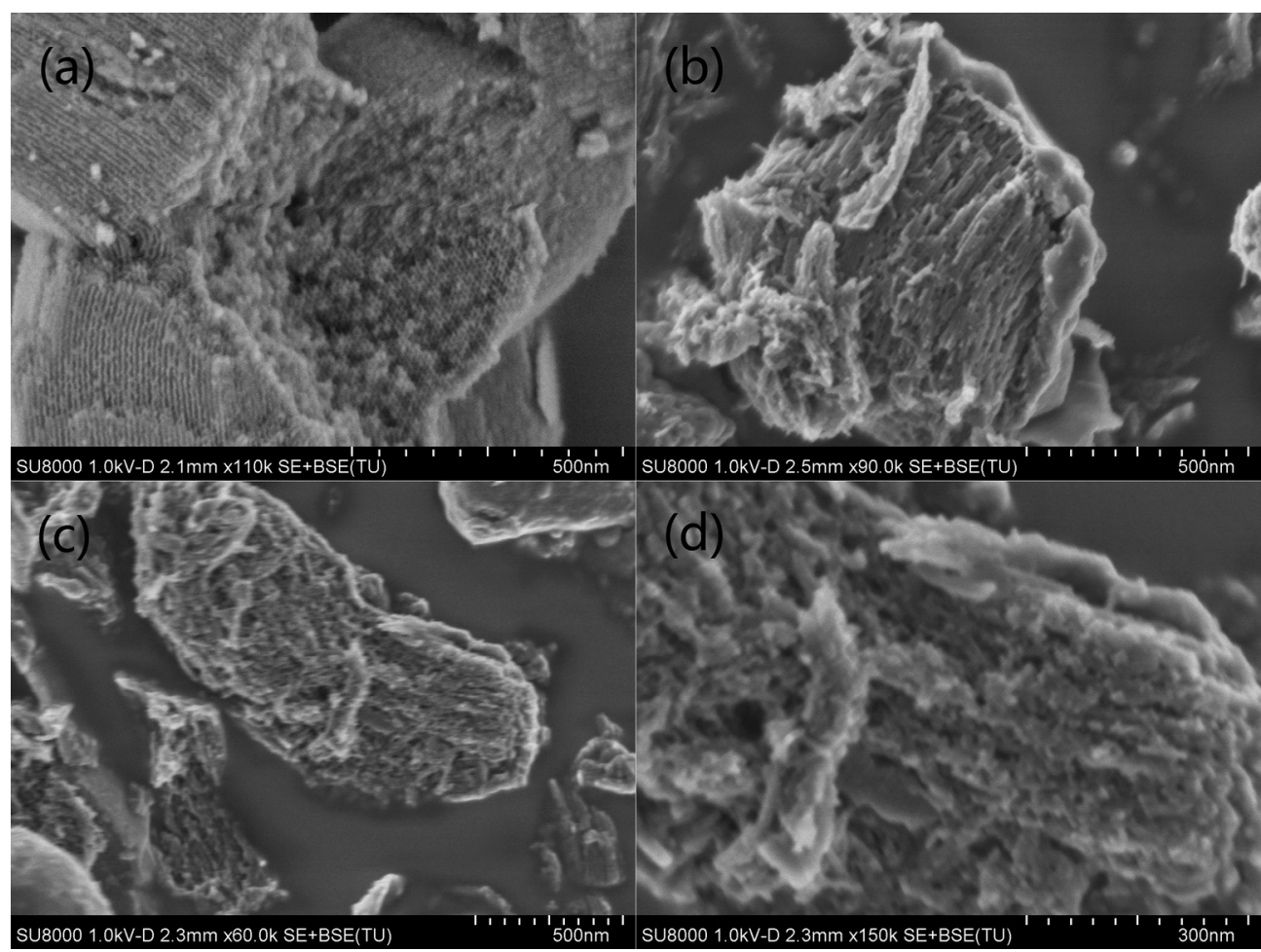

Fig. 2 FESEM images of the samples (a) SBA-15, (b) OMC8, (c) and (d) OMC-Used.

The detailed surface area and pore structure parameters of the samples are tabulated in Table 1. The differences of pore structure parameters among $\mathrm{OMC} 8, \mathrm{OMC}^{-} \mathrm{H}_{2}$ and $\mathrm{OMC}-$ $\mathrm{H}_{2} \mathrm{O}_{2}$ are negligible. The surface areas of OMCs are mainly mesopores, and the micropore surface area of OMCs might be caused by the surface defects, which is quite common in carbon materials. This was probably due to the coverage of smooth surface coke, no micropore surface area was measured for OMC-Used. Notably, the synthesized OMCs possess a highly exposed and interconnected pore structure, as illustrated in Fig. 1. This kind of pore structure could facilitate the diffusion of gas, ${ }^{26}$ and increase the accessible surface for reaction. Due to the formation of coke, the surface area and pore volume of OMC-Used are obviously lower than that of OMC8.

Raman spectra could be employed to analyze the dimensions and ordering of carbon nanomaterials. As shown in Fig. 4(b) the Raman spectrum of the carbon samples were measured before use. The G-band at $1590 \mathrm{~cm}^{-1}$ could be assigned to a mixed $\mathrm{sp}^{2} / \mathrm{sp}^{3}$ carbon structure and the D-band at $1400 \mathrm{~cm}^{-1}$ resulting from disordered and amorphous $\mathrm{sp}^{2}$ carbon. ${ }^{37}$ The D/G-band intensity ratios are commonly used to qualitatively estimate the ordering of carbon materials. After being used, there was an obvious decrease of D-band, indicating that the generated coke was a kind of better ordered carbon phase than OMC8, which agrees well with the wide angle XRD results.

The textural characterizations results proved that the OMCs have successfully replicated the pore structure of SBA15; modification did not change the structure of OMCs, and after being used as catalyst the coke, which is a better ordered carbon phase, was generated on the surface of nanorods.

\subsection{Surface property characterizations}

According to previous reports, ${ }^{31}$ it is widely accepted that the oxygen-containing functional groups are the dominating active sites for the reaction of butane dehydrogenation. In order to study the relationship between the O-doping and the reaction of isobutane dehydrogenation, the surface chemical properties of the samples were investigated by XPS, and further confirmed by FTIR (Fig. S2 $\dagger$ ) and EDS measurements (Fig. S3 and Table S1 $\uparrow$ ). The detailed O1s spectra were employed to analyze the status of the samples.

The deconvolutions of the O1s spectra were analyzed as shown in Fig. 4(a). The assignments of specific features in the 01s spectra could be verified for the following six peaks: ${ }^{38-40}$ peak I $(530.3 \mathrm{eV})$, carbonyl oxygen of quinone $(\mathrm{C}=\mathrm{O})$; peak II (531.2 eV), carbonyl oxygen in ketones and aldehydes $(\mathrm{C}=\mathrm{O})$; peak III (531.9 eV), single-bonded oxygen in furan, or keto-enol tautomer (C-O-C); peak IV (532.7 eV), hydroxyl oxygen atoms in phenol, aliphatic alcohols or chemisorbed $\mathrm{H}_{2} \mathrm{O}(\mathrm{C}-\mathrm{OH})$; peak $\mathrm{V}(533.5 \mathrm{eV})$ ether-type oxygen in anhydrides and esters (C-O-C); and peak VI (534.2 eV), single-bonded oxygen in acids and esters $(\mathrm{C}-\mathrm{OH})$.

As shown in Fig. 4(a), due to the $\mathrm{H}_{2} \mathrm{O}_{2}$ oxidation treatment, increases of carbonyl and carboxyl groups at $531.2 \mathrm{eV}$ were observed for $\mathrm{OMC}-\mathrm{H}_{2} \mathrm{O}_{2}$. Meanwhile, significant changes were observed for the sample $\mathrm{OMC}-\mathrm{H}_{2}$; except for a sharp 

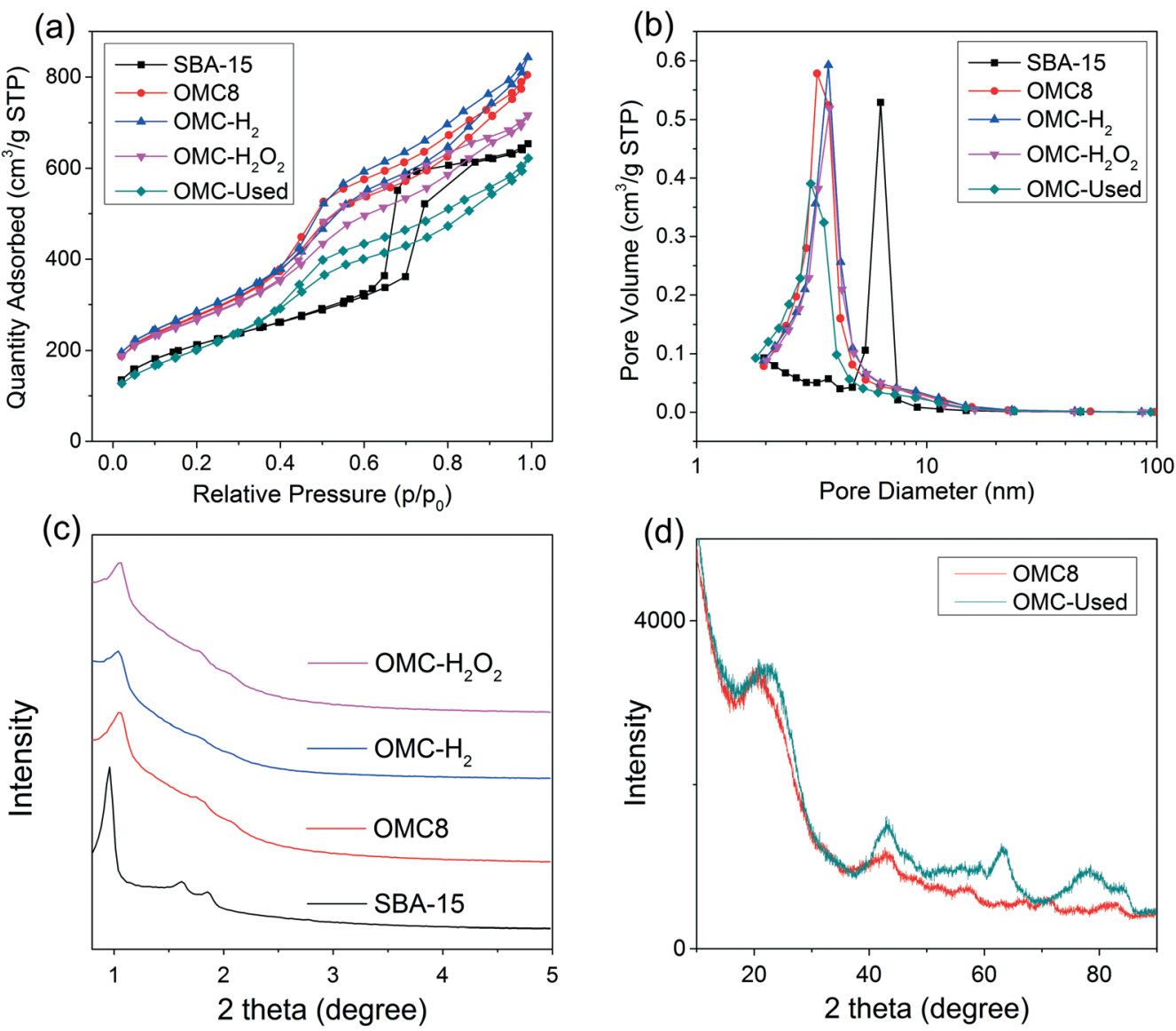

Fig. 3 (a) $\mathrm{N}_{2}$ adsorption isotherms, (b) pore size distribution and (c) small angle XRD patterns of the obtained samples; (d) wide angle XRD patterns of OMC8 and OMC-Used.

Table 1 Pore structure parameters of samples

\begin{tabular}{lcllll}
\hline Sample & Surface area ${ }^{a} \mathrm{~m}^{2} \mathrm{~g}^{-1}$ & Pore volume $^{b} \mathrm{~cm}^{3} \mathrm{~g}^{-1}$ & Micropore area $^{c} \mathrm{~m}^{2} \mathrm{~g}^{-1}$ & External area $^{d} \mathrm{~m}^{2} \mathrm{~g}^{-1}$ & Average pore size $^{e} \mathrm{~nm}^{-}$ \\
\hline SBA-15 & 721.9 & 1.01 & 65.3 & 663.9 & 5.52 \\
OMC & 973.1 & 1.24 & 85.4 & 887.7 & 4.43 \\
OMC- $_{2}$ & 1003.3 & 1.30 & 100.8 & 902.5 & 4.61 \\
OMC- $_{2} \mathrm{O}_{2}$ & 931.0 & 1.11 & 116.9 & 814.1 & 4.34 \\
OMC-Used & 760.0 & 0.96 & 0 & 760.0 & 4.18
\end{tabular}

${ }^{a}$ BET surface area. ${ }^{b}$ Total pore volume measured at $P / P_{0}=0.995 .{ }^{c}$ Microporous surface area derived from $t$-plot method. ${ }^{d}$ Mesoporous surface area, $d>2 \mathrm{~nm} .{ }^{e}$ Average pore size calculated by $4 V_{\text {total }} / S_{\mathrm{BET}}$.

decrease of $O$ content (Table 2), the peak of carbonyl groups at $530.3 \mathrm{eV}$ had disappeared. According to Zhou's report, ${ }^{41}$ the hydrogen reduction treatment at $800{ }^{\circ} \mathrm{C}$ could effectively remove almost all the various oxygen-containing groups on the activated carbon's surface. The trace amount of $\mathrm{O}$ content in $\mathrm{OMC}-\mathrm{H}_{2}$ might be caused by chemisorbed water during XPS analysis, which would be eliminated at reaction temperature, and have no effect on the DDH reaction. In addition, O1s spectra of the used sample OMCUsed were also studied, and in comparison with OMC8 the peaks for carbonyl at $530.3 \mathrm{eV}$ and carboxyl groups at 531.2 $\mathrm{eV}$ had disappeared. That might be due to the coverage of generated coke, which has no carbonyl groups on the surface.

The detailed surface elemental compositions of samples measured by XPS are tabulated in Table 2. As shown in Table 2, the oxygen content varied along with the different modification method. Compared with OMC8, there was an increase of $\mathrm{O}$ content for $\mathrm{OMC}-\mathrm{H}_{2} \mathrm{O}_{2}$, and this might be due to the $\mathrm{H}_{2} \mathrm{O}_{2}$ treatment having effectively increased the surface oxygenic functional groups. On the contrary, for the sample OMC- $\mathrm{H}_{2}$, the $\mathrm{H}_{2}$ treatment at $800{ }^{\circ} \mathrm{C}$ had effectively eliminated the surface O-doping. After being used as catalyst the O content dropped effectively to $1.01 \%$, from $3.03 \%$. These 
(a)

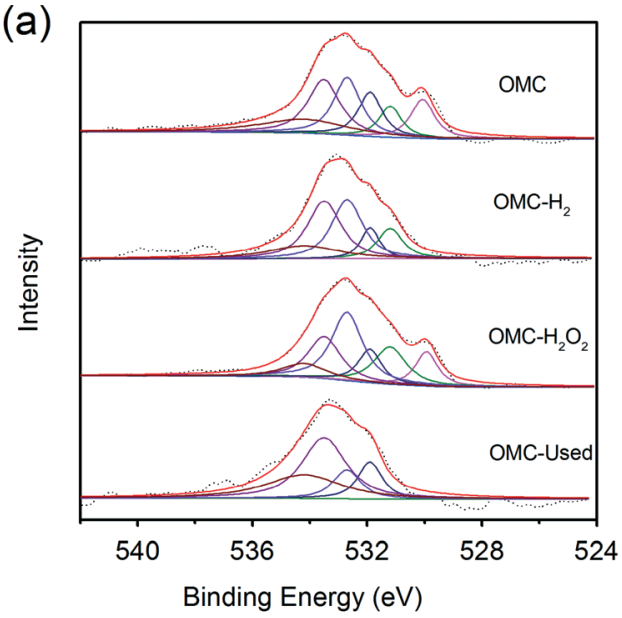

(b)

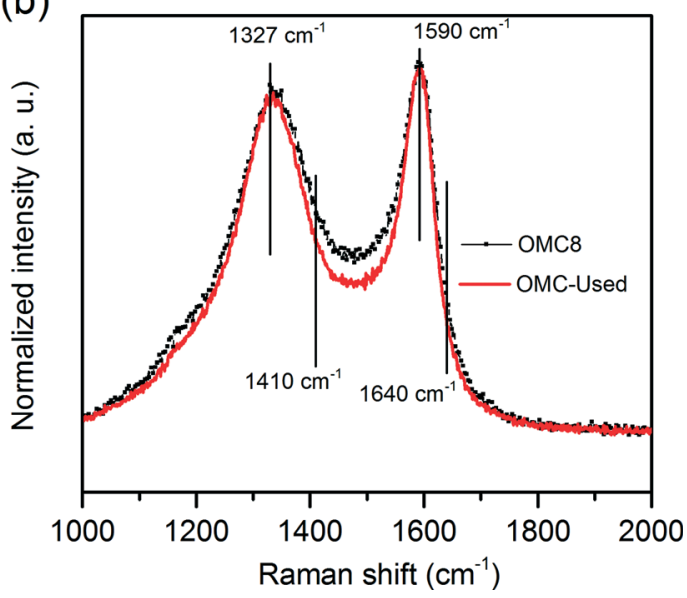

Fig. 4 (a) Superposition of O1s spectra of the samples, (b) Raman spectra of the carbon catalyst before and after use.

changes could also be observed in the overview XPS spectra, shown in Fig. S2(b). $\dagger$ The content of the elements which could be introduced during the synthesis process such as $\mathrm{Si}$ and $\mathrm{F}$ are negligible, which agrees well with the EDS results, as shown in Table S1 and Fig. S3.† These results prove the reaction activity was caused by the carbons, instead of these possibly introduced elements, such as $\mathrm{Si}$ and $\mathrm{F}$.

In summary, the textural and surface properties of samples were characterized in detail, and various changes were observed. The surface property characterization results indicate that the surface chemical properties of the carbon samples varied due to the different treatments. Significant changes to the textural and surface properties of the samples were observed after being used as catalyst. These differences of pore structure and surface properties were employed to study the possible mechanism of activated carbon catalyzed direct isobutane dehydrogenation reaction.

\subsection{Catalytic performance evaluation}

3.3.1. OMCs catalytic performances on DDH of isobutane. In order to explore the suitable reaction temperature for the isobutene direct dehydrogenation over carbon-based catalysts, the catalytic activities of OMC8 at different reaction temperatures were investigated, as shown in Fig. 5. In the range of $600-700{ }^{\circ} \mathrm{C}$, the temperature was held for $60 \mathrm{mi}-$ nutes at each increment of ten degrees centigrade. As shown in Fig. 5, there is a continuous increase of yield with the rise of reaction temperature, until the reaction temperature

Table 2 XPS surface atomic concentrations of samples

\begin{tabular}{llllll}
\hline & \multicolumn{6}{l}{ Relative atomic concentrations (\%) } \\
\cline { 2 - 6 } Sample & $\mathrm{C}$ & $\mathrm{O}$ & $\mathrm{Si}$ & $\mathrm{Cl}$ & $\mathrm{Co}$ \\
\hline OMC8 & 96.11 & 3.03 & 0.45 & 0.10 & 0.31 \\
${\text { OMC- } \mathrm{H}_{2}}$ & 98.88 & 0.87 & 0.22 & 0.03 & 0 \\
${\text { OMC- } \mathrm{H}_{2} \mathrm{O}_{2}}$ & 94.38 & 4.52 & 0.57 & 0.05 & 0.48 \\
OMC-Used & 98.70 & 1.01 & 0.24 & 0.05 & 0
\end{tabular}

reached $670{ }^{\circ} \mathrm{C}$. At higher reaction temperature the increase of conversion was at the cost of selectivity, leading to an increase of side reactions, such as cracking. After a comprehensive consideration, $620^{\circ} \mathrm{C}$ was chosen as the most appropriate reaction temperature. At $620{ }^{\circ} \mathrm{C}$, the conversion of isobutene dehydrogenation over OMC8 could reach up to $38 \%$, with a relatively good selectivity of $81 \%$, and the yield was about $31 \%$. The following catalytic performance measurements were carried out at $620^{\circ} \mathrm{C}$ as a representative reaction temperature.

Under the reaction conditions applied, the results of conversion and selectivity of the isobutene over different catalysts are shown in Fig. 6(a). The conversions of isobutane are in the order of $\mathrm{OMC}-\mathrm{H}_{2} \mathrm{O}_{2}>\mathrm{OMC} 8>\mathrm{OMC}-\mathrm{H}_{2}$, indicating that the different surface properties have influenced their reaction activities. The corresponding composition of output gas are tabulated in Table S2. $\dagger$ The higher conversion of OMC- $\mathrm{H}_{2} \mathrm{O}_{2}$ might be due to the existence of abundant oxygen-containing functional groups, meanwhile the content of $\mathrm{C}_{2}$ and $\mathrm{C}_{3}$ are also higher than that of other catalysts, as

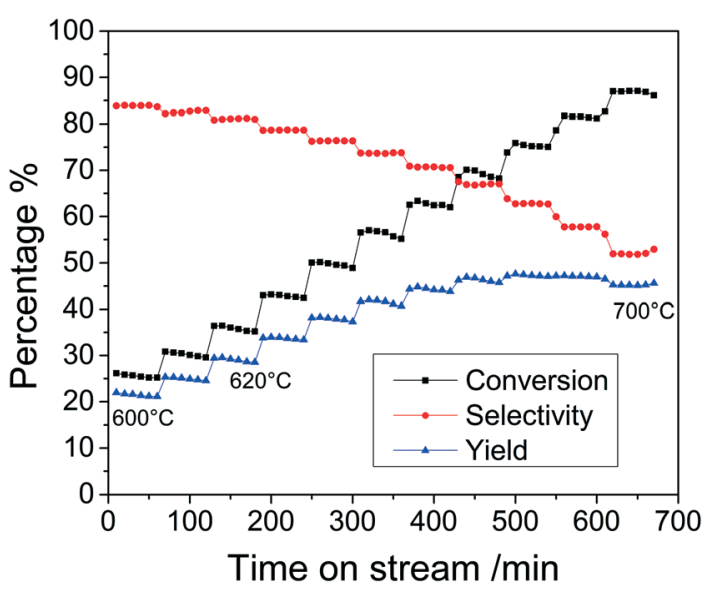

Fig. 5 The influence of reaction temperature on the activity of OMC8 catalyzed DDH reaction. 

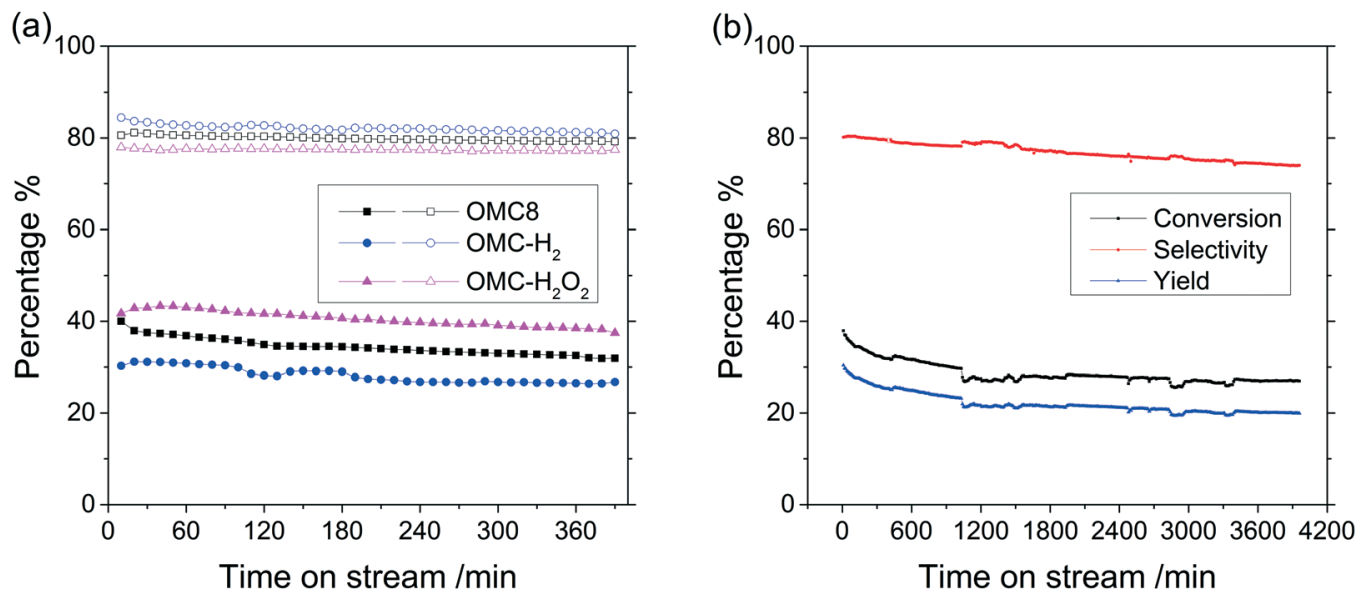

Fig. 6 (a) Time on stream conversion (filled symbols) and selectivity (open symbols) of isobutane DDH reaction over different carbon-based catalysts, (b) retention rate of $\mathrm{OMC} 8$ at $620^{\circ} \mathrm{C}$ for 4000 minutes.

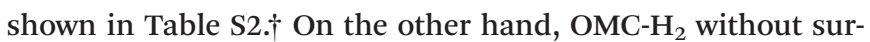
face oxygen-containing functional groups still maintained relatively good conversion and selectivity, indicating that the O-doping is not an absolutely necessary factor, though it enhanced the reaction to some extent as reflected by the activity of $\mathrm{OMC}-\mathrm{H}_{2} \mathrm{O}_{2}$.

The catalytic retention rate of the carbon-based catalysts was measured by choosing OMC8 as a representative, as shown in Fig. 6(b). The reaction of isobutane direct dehydrogenation was continuously measured at $620{ }^{\circ} \mathrm{C}$ for $4000 \mathrm{mi}-$ nutes. The initial conversion over OMC8 was about $38 \%$ with a high selectivity of $81 \%$, and the conversion was $27 \%$ with a selectivity of $74 \%$ after reacting for 4000 minutes. In our previous work, reaction activities of carbon-based catalysts were compared with $\mathrm{Cr}_{2} \mathrm{O}_{3} / \mathrm{Al}_{2} \mathrm{O}_{3}$ catalyst, the conversion of catalyst $\mathrm{Cr}_{2} \mathrm{O}_{3} / \mathrm{Al}_{2} \mathrm{O}_{3}$ decreased by $80 \%$ of its original value within 500 minutes. ${ }^{34}$ For OMC8, after 1200 minutes of reaction, the conversion of the reaction reached a steady level, and in the following 2800 minutes the decrease of conversion was less than $2 \%$. As shown in Fig. 6(b). The good retention rate might be resulting from the easily accessible active sites that universally exist on the surface of carbon materials.

3.3.2. Insights into the catalytic behaviours of OMCs. It has been reported that ketonic $(\mathrm{C}=\mathrm{O})$ groups were the dominate active sites in the reaction of the ODH of $n$-butane. ${ }^{31}$ According to our research, the introduction of oxygencontaining functional groups also increased the activity of isobutane $\mathrm{DDH}$ to some extent. However, the $\mathrm{OMC}-\mathrm{H}_{2}$ without surface oxygen-containing functional groups also maintained a high activity. So we believe except for the oxygen-containing functional groups, the carbon itself was also active for the isobutane $\mathrm{DDH}$ reaction, and the latter provided the large proportion of the observed activity.

The active sites on the surface of carbon materials which dominated the activity might be the defects which universally exist on the surface of carbon materials. According to Su's report, ${ }^{42}$ the carbon materials, with a variable $\mathrm{sp}^{2}-/ \mathrm{sp}^{3}$-carbon ratio, possessed lots of defects/vacancies on its surface, which could act as active sites for the DDH of propane. Coke might also contained a certain amount of defects/vacancies, which kept the reaction activity at a relatively low level. Similar results were reported by McGregor, ${ }^{32}$ that the deposited coke was active in the dehydrogenation of $n$-butane on $\mathrm{VO}_{x} / \mathrm{Al}_{2} \mathrm{O}_{3}$ catalyst. According to the XRD and Raman results (Fig. 3d and $4 \mathrm{~b}$ ), the coke generated on the surface of nanorods showed a different crystallinity which was closer to graphite when compared with OMC8. A research related to carbon catalysts $^{43}$ demonstrated that the catalytic activity of carbon materials could be influenced by the crystal surface of carbon materials. The generated coke might have a better-ordered structure, which might have less defects/vacancies. So coke with a lower density of defects/vacancies might have lower activity.

In summary, the defects/vacancies, which universally exist on the surface of carbon materials, might be the active sites responsible for the DDH of isobutane. During the DDH reaction, coke was generated on the surface of activated carbon, and the newly formed coke with less defects/vacancies led to lower catalytic activity. The good retention rate might be due to the fact that the surface area reached a steady state value though the coke is still being generated.

3.3.3. Prospect of the carbon-based catalysts for DDH. Compared with the industrial catalysts currently in use, carbon-based catalysts could keep a good retention rate for a long time, and avoid the release of toxic metal oxide or loss of noble metals. Besides, the reaction activity could be further developed by optimizing their pore structure and surface property. The introduction of heteroatoms, such as by P-doping $^{29}$ into carbon-based catalysts, might be able to further enhance their reaction activity. The suitable pore structure could be realized by employing a different preparation method, and the surface property could be varied by employing different precursors or post-processing treatments.

The main limitation for using carbon-based materials as catalysts might be the lack of a practicable regeneration 
method, since the conventional burning method for metal oxide catalysts is not applicable. According to Zhou's report ${ }^{41}$ the carbon materials could be regenerated by stagnant oxygen containing gases at $400-600{ }^{\circ} \mathrm{C}$. Besides, we believe that the retention rate of carbon materials could be further extended by using customized carbon materials, which could tolerate large amounts of coke without an obvious decrease of surface area. The carbon materials should have a high surface area to guarantee a high initial catalytic activity, a large pore volume and a big pore width to tolerate the formation of coke and avoid the decrease of surface area or blockage of pores for a long period of time. Advantages of carbon-based catalysts, such as their low cost, reproducibility and environmental friendliness, make it possible to use disposable carbon-based catalysts as an alternative solution.

\section{Conclusions}

In summary, a series of modified ordered mesoporous carbons (OMCs) with different oxygen contents were employed to study the carbon catalyzed direct dehydrogenation of isobutane. The OMCs were found to be highly active toward the DDH reaction, and the possible active sites were confirmed by analyzing the changes of pore structure and surface properties. The oxygen-containing functional groups enhanced the dehydrogenation reaction to some extent, but the activity was mainly provided by the defects/vacancies on the surface of carbon materials. The generated coke was found to be active at a relatively lower level, which might be responsible for the good retention rate. In this study, carbon-based catalysts showed some interesting possibilities, making it possible for them to be used as an alternative solution for isobutane direct dehydrogenation.

\section{Acknowledgements}

This work was financially supported by the National Natural Science Foundation $(21337003,21477149,21577158)$, the Strategic Priority Research Program of the Chinese Academy of Sciences (No. XDB05050200) and Special Environmental Protection Foundation for Public Welfare Project (201309073).

\section{References}

1 W. C. White, Chem.-Biol. Interact., 2007, 166, 10.

2 J. Urschey, Appl. Catal., A, 2003, 252, 91.

3 G. Wang, C. Xu and J. Gao, Fuel Process. Technol., 2008, 89, 864.

4 L. M. Madeira and M. F. Portela, Catal. Rev.: Sci. Eng., 2002, 44, 247.

5 M. M. Bhasin, J. H. Mccain, B. V. Vora, T. Imai and P. R. Pujadó, Appl. Catal., A, 2001, 221, 397.

6 L. Li and Z. Yan, Prog. Chem., 2005, 17, 651.

7 J. M. Mcnamara, S. David Jackson and D. Lennon, Catal. Today, 2003, 81, 583.

8 S. Davidjackson, Chem. Eng. J., 2006, 120, 119.
9 N. O. Elbashir, S. M. Al-Zahrani, A. E. Abasaeed and M. Abdulwahed, Chem. Eng. Process., 2003, 42, 817.

10 D. B. Fox, E. H. Lee and M. H. Rei, Ind. Eng. Chem. Prod. Res. Dev., 1972, 11, 444.

11 M. Farsi, A. Jahanmiri and M. R. Rahimpour, Theor. Found. Chem. Eng., 2014, 48, 799.

12 J. J. Sattler, J. Ruiz-Martinez, E. Santillan-Jimenez and B. M. Weckhuysen, Chem. Rev., 2014, 114, 10613.

13 S. Wang and Z. H. Zhu, Energy Fuels, 2004, 18, 1126.

14 R. Iezzi, F. Buonomo and D. Sanfilippo, US Pat., 5143886, 1992.

15 P. M. Fritz, H. V. Boelt, H. Hackner and D. G. J. Van, EP. Pat., 0947247, 1999.

16 M. E. Harlin, V. M. Niemi and A. O. I. Krause, J. Catal., 2000, 195, 67.

17 R. Yuan, Y. Li, H. Yan, H. Wang, J. Song, Z. Zhang, W. Fan, J. Chen, Z. Liu, Z. Liu and Z. Hao, Chin. J. Catal., 2014, 35, 1329.

18 Y. Takita, K.-I. Sano, K. Kurosaki, N. Kawata, H. Nishiguchi, M. Ito and T. Ishihara, Appl. Catal., A, 1998, 167, 49.

19 Y. Takita, K.-I. Sano, T. Muraya, H. Nishiguchi, N. Kawata, M. Ito, T. Akbay and T. Ishihara, Appl. Catal., A, 1998, 170, 23.

20 M. E. Harlin, A. O. I. Krause, B. Heinrich, C. Pham-Huu and M. J. Ledoux, Appl. Catal., A, 1999, 185, 311.

21 A. Kaddouri, C. Mazzocchia and E. Tempesti, Appl. Catal., A, 1998, 169, L3.

22 X. Wu, J. Zhou, W. Xing, G. Wang, H. Cui, S. Zhuo, Q. Xue, Z. Yan and S. Z. Qiao, J. Mater. Chem., 2012, 22, 23186.

23 Z. Zhang, J. Zhou, W. Xing, Q. Xue, Z. Yan, S. Zhuo and S. Z. Qiao, Phys. Chem. Chem. Phys., 2013, 15, 2523.

24 H. Xie, Z. Wu, S. H. Overbury, C. Liang and V. Schwartz, J. Catal., 2009, 267, 158.

25 R. P. Rocha, J. Restivo, J. P. S. Sousa, J. J. M. Órfão, M. F. R. Pereira and J. L. Figueiredo, Catal. Today, 2015, 241, 73.

26 K. Jurewicz, C. Vix-Guterl, E. Frackowiak, S. Saadallah, M. Reda, J. Parmentier, J. Patarin and F. Béguin, J. Phys. Chem. Solids, 2004, 65, 287.

27 D. Chen, A. Holmen, Z. Sui and X. Zhou, Chin. J. Catal., 2014, 35, 824.

28 I. Gniot, P. Kirszensztejn and M. Kozłowski, Appl. Catal., A, 2009, 362, 67.

29 V. Schwartz, H. Xie, H. M. Meyer, S. H. Overbury and C. Liang, Carbon, 2011, 49, 659.

30 J. De Jesús Díaz Velásquez, L. M. C. Suárez and J. L. Figueiredo, Appl. Catal., A, 2006, 311, 51.

31 J. Zhang, X. Liu, R. Blume, A. Zhang, R. Schlogl and D. S. Su, Science, 2008, 322, 73.

32 J. Mcgregor, Z. Huang, E. P. J. Parrott, J. A. Zeitler, K. L. Nguyen, J. M. Rawson, A. Carley, T. W. Hansen, J.-P. Tessonnier and D. S. Su, J. Catal., 2010, 269, 329.

33 X. Liu, B. Frank, W. Zhang, T. P. Cotter, R. Schlogl and D. S. Su, Angew. Chem., Int. Ed., 2011, 50, 3318.

34 Y. Li, Z. Zhang, J. Wang, C. Ma, H. Yang and Z. Hao, Chin. J. Catal., 2015, 36, 1214.

35 D. Zhao, Science, 1998, 279, 548. 
36 W. Xing, S. Z. Qiao, R. G. Ding, F. Li, G. Q. Lu, Z. F. Yan and H. M. Cheng, Carbon, 2006, 44, 216.

37 V. Mochalin, S. Osswald and Y. Gogotsi, Chem. Mater., 2009, 21, 273.

38 S. Reiche, R. Blume, X. C. Zhao, D. Su, E. Kunkes, M. Behrens and R. Schlögl, Carbon, 2014, 77, 175.

39 D. Rosenthal, M. Ruta, R. Schlögl and L. Kiwi-Minsker, Carbon, 2010, 48, 1835.
40 S. Kundu, Y. Wang, W. Xia and M. Muhler, J. Phys. Chem. C, 2008, 112, 16869.

41 J.-H. Zhou, Z.-J. Sui, J. Zhu, P. Li, D. Chen, Y.-C. Dai and W.-K. Yuan, Carbon, 2007, 45, 785.

42 R. Wang, X. Sun, B. Zhang, X. Sun and D. Su, Chem. - Eur. J., 2014, 20, 6324.

43 B. Zhong, J. Zhang, B. Li, B. Zhang, C. Dai, X. Sun, R. Wang and D. S. Su, Phys. Chem. Chem. Phys., 2014, 16, 4488. 